\title{
Modeling Breakthrough Curves of Citric Acid Adsorption onto Anionic Resins in an Aqueous Solution
}

\author{
Sohrabali Ghorbanian, ${ }^{1}$ Mostafa Davoudinejad, ${ }^{1}$ Amir Khakpay, ${ }^{1}$ and Saeidreza Radpour ${ }^{2}$ \\ ${ }^{1}$ Faculty of Engineering, University of Tehran, P.O. Box 11365/4563, Tehran, Iran \\ ${ }^{2}$ Engineering Department, University of Alberta, Edmonton, AB, Canada T6G $2 G 8$ \\ Correspondence should be addressed to Amir Khakpay; amir.khakpay@ut.ac.ir
}

Received 14 May 2014; Accepted 11 January 2015

Academic Editor: Mohammed A. Gondal

Copyright (c) 2015 Sohrabali Ghorbanian et al. This is an open access article distributed under the Creative Commons Attribution License, which permits unrestricted use, distribution, and reproduction in any medium, provided the original work is properly cited.

Breakthrough curves for citric acid adsorption from aqueous solution onto ion-exchange resin at 20,35 , and $55^{\circ} \mathrm{C}$ have been investigated. To predict breakthrough curves, three mathematical models have been analyzed based on the values of the least square method parameters, Durbin-Watson test, and mean relative percent error and, finally, appropriate models have been achieved. Models are in good agreement with experimental data based on the results. To examine models reliabilities and accuracy, models have been compared by various breakthrough curve data obtained by other investigators. The results show appropriate agreement and in some cases regression errors have been reduced to less than 1.0 percent.

\section{Introduction}

Organic compounds have been excessively released into the environment because of the rapid industrialization and have caused a major global concern $[1,2]$. One of the most widely used organic acids in the field of foods and beverages as an acidulant as well as in pharmaceutical and chemical products is citric acid. Aspergillus niger was mainly used to produce citric acid by surface or submerged fungal fermentation. However, citric acid was produced with the submerged fermentation method $[3,4]$.

Citric acid is the most important produced organic acid and there is a great worldwide demand for citric acid consumption because of its low toxicity compared with other acidulants used in the pharmaceutical and food industries [5]. Therefore, waste from food and pharmaceutical industries contains citric acid. In natural water systems, organic acids can stick heavy metal ions on solid surfaces by forming complexes. This process prevents the preservation of heavy metals by sediments [2]. Citric acid and acetic acid are known as organic ligands involved in the adsorption process in the soil chemistry [2].

Conventional methods for separating organic compounds are chemical precipitation, electrolysis, membrane separation, ion exchange, and absorption by activated carbon [6-9]. High capital or high operational cost or disposal of resulting sludge are disadvantages of most of these methods. In recent years, more and more attention has been paid for the investigation of low-cost materials such as agricultural by products, industrial wastes, and biological materials as adsorbents $[10,11]$. Recently, modified cellulose beads and resins were utilized to adsorb some heavy metallic ions $[12,13]$. Adsorption process has lower production costs for purification of organic acids particularly citric acid in comparison with that of other methods $[14,15]$.

Resin adsorption chromatography using different synthetic resins has been utilized to isolate and separate organic compounds with varying degrees of success. This chromatographic separation method concentrates and isolates organic compounds into operationally defined fractions depending on their relation to different resins and their back elution efficiencies [16-18]. Although the principle of organic acids separation by ion-exchange method has been known, there are many details that require development and determination. Thus, it seems that simulated moving bed (SMB) is suitable and effective by using chromatography method on the base of countercurrent continuous contact between feed and adsorbent $[19,20]$. 
One of the continuous chromatographic methods is SMB. Parameters such as ion-exchange resins properties, adsorption equilibrium data, and operation characteristics of bed are necessary to be determined for SMB method. One of the best methods to determine and optimize operating parameters is preparing fitting mathematical model from actual processes. Generally, in such models, mass transfer in liquid layer outside the resin particles is negligible. The general ion-exchange reaction of resin is presented in [22-24]

$$
\mathrm{R}-\mathrm{N}+\mathrm{CH}_{n} \longleftrightarrow \mathrm{R}-\mathrm{NH}^{+} \mathrm{CH}_{n-1}{ }^{-} .
$$

For acids with more than one carboxyl group and also for R$\mathrm{N}$ in (1) base resins are appropriate [25].

In present study, breakthrough curves for citric acid adsorption from aqueous solution onto ion-exchange resin at different temperatures have been investigated. Then, several mathematical models have been developed and analyzed to predict system properties based on experimental data.

\section{Breakthrough Curves}

Equations already proposed for describing breakthrough curves are complicated expressions that are just valid for ideal, symmetrical breakthrough curves and for other possible shapes of breakthrough curves and they are unable to generate agreeable results. These equations in some cases were determined from mass balance equations along with some simplification assumptions $[26,27]$ that often were introduced for gas breakthrough curves or include additional fitting constants to obtain better explanation of asymmetric (skewed) breakthrough curves like Wood equation and others are only mathematical equations that produce " $S$ " shape curves $[28,29]$.

In this research work, it was tried to derive mathematical equations that not only can predict symmetrical "S" shape breakthrough curves but also can explain other curves that deviate from. In addition, we derived and statistically investigated different forms of several models such as fractional, polynomial, and exponential. Finally, three new implicit mathematical fitting models in following forms were derived for determination of breakthrough curves. Derived implicit models are shown in (2) through (4). Parameters $D, E, F, G$, $H, I, m, p$, and $q$ are fitting constant parameters that must be obtained by regression of the experimental data:

$$
\begin{aligned}
& \frac{C}{C_{0}}=\frac{D \ln (1+t)}{E+\left(C / C_{0}\right)^{m}} \\
& \frac{C}{C_{0}}=\frac{F t+G}{1+\left(C / C_{0}\right)^{p}} \\
& \frac{C}{C_{0}}=\frac{H \ln (1+t)+I}{1+\left(C / C_{0}\right)^{q}} .
\end{aligned}
$$

\section{Experimental}

All of the experimental data which was used in the current study was determined from our previous study [21]. The
TABLE 1: Diffusivities and resin saturation capacity at different temperatures [21].

\begin{tabular}{lcc}
\hline$T\left({ }^{\circ} \mathrm{C}\right)$ & $D_{p} \times 10^{10}\left(\mathrm{~m}^{2} / \mathrm{s}\right)$ & $C_{m}(\mathrm{~g} / \mathrm{L})$ \\
\hline 20 & 3.1 & 302.2 \\
35 & 4.3 & 265.1 \\
55 & 6.1 & 190.4 \\
\hline
\end{tabular}

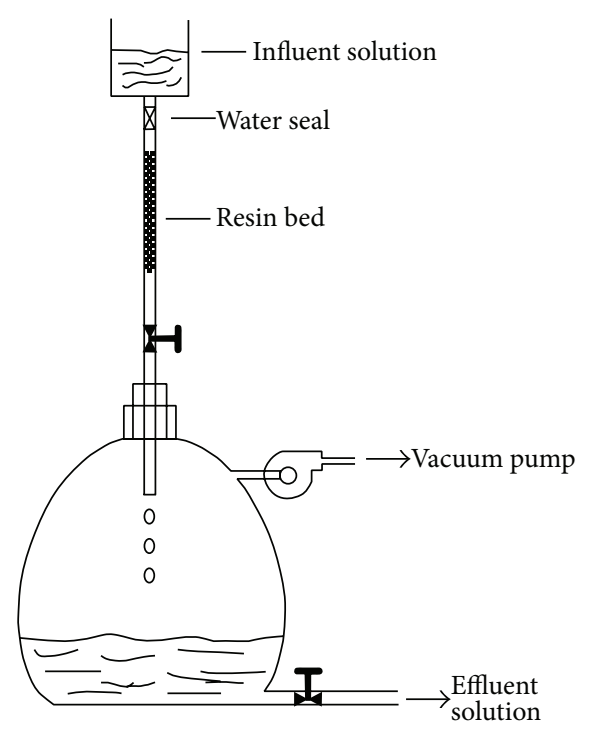

FIGURE 1: Schematic diagram of experimental apparatus [21].

experimental apparatus includes a glass column (ID $=1 \mathrm{~cm}$, height $=20 \mathrm{~cm})$ and a bed $\left(\right.$ volume $\left.=15 \mathrm{~cm}^{3}\right)$. Figure 1 shows a schematic diagram of the used apparatus in our experiments. The volumetric flow rate of acid in adsorption and desorption was constant and was equal to $1.5 \mathrm{~mL} / \mathrm{min}$. Furthermore, the experiments were done at three different temperatures (20, 35 , and $55^{\circ} \mathrm{C}$ ). Approximately, 25 samples were analyzed for each temperature. The concentration of citric acid in the influent solution was $\% 2 \mathrm{wt}$ and elution process is carried out by 0.2 molar sulfuric acid solution. In addition, the concentration of citric acid was obtained by a spectrophotometer UV-VIS (model: Cary 1E/Cary 3E, purchased from Varian Co.). All of experiments were performed three times to examine reproducibility and repeatability of the experiments.

\section{Results and Discussion}

In this study, the breakthrough curves have been studied at three different temperatures 20,35 , and $55^{\circ} \mathrm{C}$ [21]. It has been observed that weak basic resins have a better performance in citric acid recovery in water solution. Also, the diffusivity of citric acid and resin saturation capacity have been obtained. These results have been shown in Table 1 for different temperatures [21].

The constant values of all models have been obtained by "EViews software" version 3.1 [30]. It should be mentioned that number 1 has been added to the logarithmic terms because of having the value of function at point $(1,1)$. Least 
TABLE 2: Models fitting results for citric acid data.

\begin{tabular}{lcccccccccc}
\hline \multirow{2}{*}{ Models } & \multicolumn{3}{c}{$T=20^{\circ} \mathrm{C}$} & \multicolumn{3}{c}{$T=35^{\circ} \mathrm{C}$} & \multicolumn{3}{c}{$T=55^{\circ} \mathrm{C}$} & Average MRPE \\
& $\% R^{2}$ & D.W. & MRPE & $\% R^{2}$ & D.W. & MRPE & $\% R^{2}$ & D.W. & MRPE & 1.75 \\
\hline Equation (2) & 99.96 & 0.650 & 5.40 & 99.97 & 0.543 & 3.88 & 99.99 & 1.11 & 13.68 \\
\hline Equation (3) & 99.88 & 0.491 & 13.60 & 99.88 & 0.529 & 11.26 & 99.93 & 0.848 & 13.33 & 12.73 \\
\hline Equation (4) & 99.92 & 0.576 & 11.76 & 99.90 & 0.560 & 10.54 & 99.93 & 0.807 & 14.68 & 12.33 \\
\hline
\end{tabular}

TABLE 3: Calculation results of the coefficients of (2) at temperatures 20,35 , and $55^{\circ} \mathrm{C}$.

\begin{tabular}{lcccc}
\hline Models & Equation parameters & $20^{\circ} \mathrm{C}$ & $35^{\circ} \mathrm{C}$ & $55^{\circ} \mathrm{C}$ \\
\hline \multirow{3}{*}{ Equation (2) } & $D$ & 0.177 & 0.163 & 0.135 \\
& $E$ & 0.485 & 0.357 & 0.112 \\
& $M$ & -1.108 & -1.086 & -1.014 \\
\hline
\end{tabular}

square method has been used for curve fitting and required statistical tests have been done on the results. $R$-squared and Durbin-Watson test values have been considered in function analyzing.

The $R$-squared $\left(R^{2}\right)$ statistic is measuring the capability of developed mathematical models in predicting the coefficient values in the function. This value will be equal to one (or $\% 100)$ for a perfect curve fitting.

Durbin-Watson test (D.W.) is useful to analyze the residual values which are the difference between the experimental results and model amount in each point. If there are harmonic changes in residual values, it might need to add another variable in the function to cover the variable amounts.

Another analyzed factor in this modeling is mean relative percent error, MRPE. It has been done to analyze the results of different developed function. The lower MRPE, the more efficient mathematical function in modeling. Equation (5) has been used to calculate the MRPE:

$$
\text { MRPE }=\frac{1}{N} \sum_{i=1}^{N}\left|\frac{\left(C_{t} / C_{0}\right)_{\operatorname{Exp}}-\left(C_{t} / C_{0}\right)_{\mathrm{Equ}}}{\left(C_{t} / C_{0}\right)_{\operatorname{Exp}}}\right| \times 100 .
$$

Modeling fitting results for citric acid data have been shown in Table 2. The values of $R^{2}$ are in an appropriate level very close to 1 . The results show that (2) well described the adsorption of citric acid on the IRA-93 resin.

Statistical tests show that the effectiveness of all developed equations is in an appropriate level, but (2) has better fitting results in comparison with other developed mathematical functions, especially with consideration of MRPE.

Equation (2) has been analyzed more and related constants have been estimated at 20,35 , and $55^{\circ} \mathrm{C}$. The results have been presented in Table 3. Also (2) for different temperatures has been plotted in Figure 2.

Validation of results have been done based on comparing the results with other investigation including $\mathrm{Lu}$ et al. (adsorption of $\mathrm{Pb}^{2+}$ in a fixed bed of ETS-10 adsorbent), Gonzalez et al. (adsorption of Cr(III) from aqueous solution onto Agave lechuguilla biomass), Grande et al. (adsorption of propylene in zeolite 4A), Ahmaruzzaman et al. (adsorption of phenol from wastewater by different adsorbents), Pan et al.
TABLE 4: Models fitting results for selected breakthrough curves data.

\begin{tabular}{lccc}
\hline Models & Equation (2) & Equation (3) & Equation (4) \\
\hline Averaged MRPE & 3.57 & 7.82 & 7.51 \\
\hline
\end{tabular}

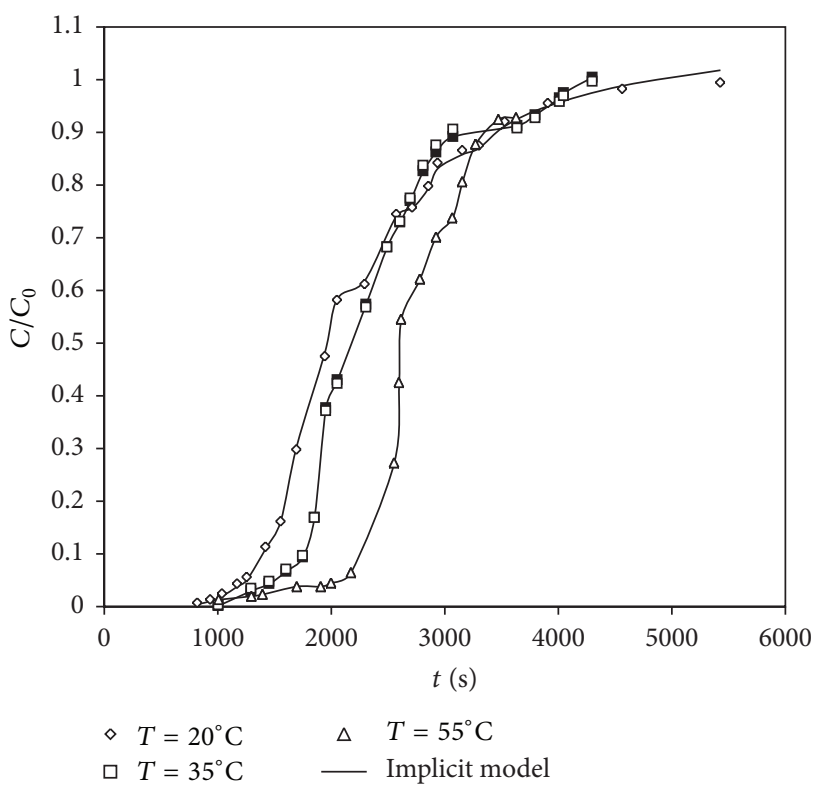

FIGURE 2: Citric acid adsorption breakthrough curves data points fitted by (2) at 20,35 , and $55^{\circ} \mathrm{C}$ [21].

(adsorption of phenol onto resin NDA-100), and Malkoc et al. (adsorption of $\mathrm{Cr}(\mathrm{VI})$ onto waste acorn of Quercus ithaburensis) breakthrough curves data [31-36]. In this case, 18 breakthrough curves were utilized in order to determine reliability of models. From this, (2), (3), and (4) were fitted to these breakthrough curves and the results are shown in Table 4.

The values of MRPE in Table 4 are in good agreement with experimental breakthrough curves. In addition, the amounts of $R^{2}$ are more than 0.99 for all of adsorbates. Similar to our breakthrough curves, (2) best fitted with experimental data and the average MRPE is 3.57. In addition, the results were plotted on Figures 3 through 8 for (2). Moreover, the calculation results for constants of (2) are presented in Table 5 .

As mentioned above, (2) has the best conformity with experimental data and properly fitted based on $R^{2}$ values close to 1.0 and low values of averaged MRPE over breakthrough curves of citric acid which is $3.68 \%$. Furthermore, 
TABLE 5: Fitting different breakthrough curves based on (2), related statistical tests, and MRPE.

\begin{tabular}{|c|c|c|c|c|c|c|c|c|}
\hline Breakthrough curve & \multicolumn{2}{|c|}{ Case } & $D$ & $E$ & $m$ & $R^{2} \%$ & D.W. & MRPE \\
\hline \multirow{2}{*}{$\begin{array}{l}\text { Adsorption of } \mathrm{Pb}^{2+} \text { onto } \\
\text { ETS-10 adsorbent }\end{array}$} & \multirow{2}{*}{$u_{s}(\mathrm{~m} / \mathrm{s})$} & $4.67 E-04$ & 0.107 & 0.074 & -1.004 & 99.99 & 0.170 & 0.45 \\
\hline & & $7.0 E-04$ & 0.115 & 0.125 & -1.021 & 99.99 & 0.310 & 0.92 \\
\hline \multirow{3}{*}{$\begin{array}{l}\text { Adsorption of } \mathrm{Cr}(\mathrm{VI}) \\
\text { onto waste acorn of } \\
\text { Quercus ithaburensis }\end{array}$} & \multirow{3}{*}{ Particle size $(\mathrm{mm})$} & $0.15-0.25$ & 0.198 & 0.499 & -1.074 & 99.99 & 0.979 & 2.46 \\
\hline & & $0.25-0.50$ & 0.203 & 0.505 & -1.054 & 99.99 & 0.819 & 2.81 \\
\hline & & $0.50-1.00$ & 0.211 & 0.546 & -1.023 & 99.93 & 0.467 & 2.34 \\
\hline \multirow{3}{*}{$\begin{array}{l}\text { Adsorption of propylene } \\
\text { onto zeolite } 4 \mathrm{~A}\end{array}$} & \multirow{3}{*}{$Q\left(\mathrm{~cm}^{3} / \mathrm{min}\right)$} & 32.0 & 0.186 & 0.474 & -1.010 & 99.99 & 0.218 & 1.38 \\
\hline & & 46.2 & 0.325 & 1.473 & -1.144 & 99.90 & 0.337 & 8.54 \\
\hline & & 62.5 & 0.291 & 1.300 & -1.174 & 99.85 & 0.220 & 5.75 \\
\hline \multirow{3}{*}{$\begin{array}{l}\text { Adsorption of phenols } \\
\text { from wastewater }\end{array}$} & \multirow{3}{*}{ Adsorbent } & Activated carbon & 0.385 & 0.396 & -1.029 & 99.94 & 0.899 & 5.59 \\
\hline & & RCP & 0.339 & 0.189 & -0.908 & 99.94 & 2.00 & 3.58 \\
\hline & & Residual coal & 0.453 & 0.564 & -0.901 & 99.59 & 0.544 & 3.61 \\
\hline \multirow{3}{*}{$\begin{array}{l}\text { Adsorption of phenol } \\
\text { onto resin NDA-100 }\end{array}$} & \multirow{3}{*}{$C_{0}(\mathrm{mmol} / \mathrm{L})$} & 0.532 & 0.290 & 0.323 & -1.070 & 99.98 & 0.346 & 4.79 \\
\hline & & 2.032 & 0.356 & 0.366 & -1.079 & 99.98 & 0.320 & 3.39 \\
\hline & & 5.319 & 0.653 & 1.234 & -1.308 & 99.32 & 0.100 & 10.44 \\
\hline \multirow{3}{*}{$\begin{array}{l}\text { Adsorption of Cr(III) } \\
\text { onto Agave lechuguilla } \\
\text { biomass }\end{array}$} & \multirow{3}{*}{ Bed length (dm) } & 0.5 & 0.257 & 0.250 & -0.999 & 99.99 & 1.93 & 0.90 \\
\hline & & 1.0 & 0.247 & 0.263 & 0.454 & 99.99 & 0.454 & 2.49 \\
\hline & & 1.5 & 0.224 & 0.203 & -1.300 & 99.99 & 0.394 & 1.17 \\
\hline
\end{tabular}

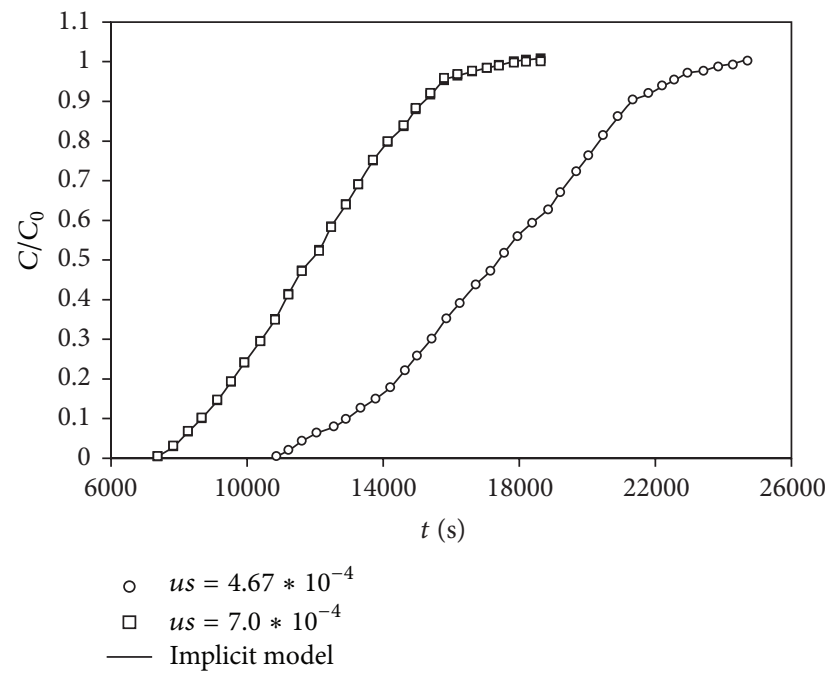

FIGURE 3: Breakthrough curves of $\mathrm{Pb}^{2+}$ adsorption onto ETS-10 at different superficial velocity fitted with (2) [31].

the MRPE for the selected breakthrough curves from various chemical systems is $3.57 \%$.

\section{Conclusions}

A statistical investigation was performed to obtain the adsorption breakthrough curves for citric acid at 20, 35, and $55^{\circ} \mathrm{C}$. Furthermore, implicit models were utilized in order to correlate breakthrough curves. The results were then analyzed and summarized as follows.

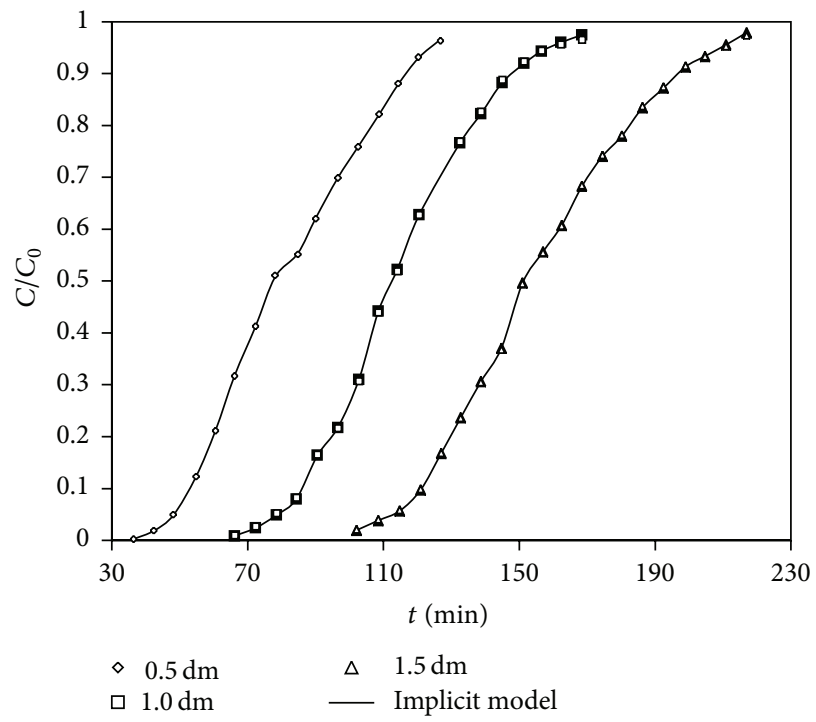

Figure 4: Breakthrough curves of $\mathrm{Cr}$ (III) adsorption onto Agave lechuguilla biomass at different bed lengths fitted with (2) [32].

Because of their structure, implicit mathematical models have good flexibility to describe various breakthrough curves with different steepness and shapes even for unusual " $\mathrm{S}$ " shape type and also can predict alteration of various adsorption breakthrough curves. As a result, logarithmic models show better conformity with experimental data in comparison with that of nonlogarithmic corresponding models. Since the numerical values of time are much greater than concentration ratio, taking logarithm of time reduces its amount and arises 


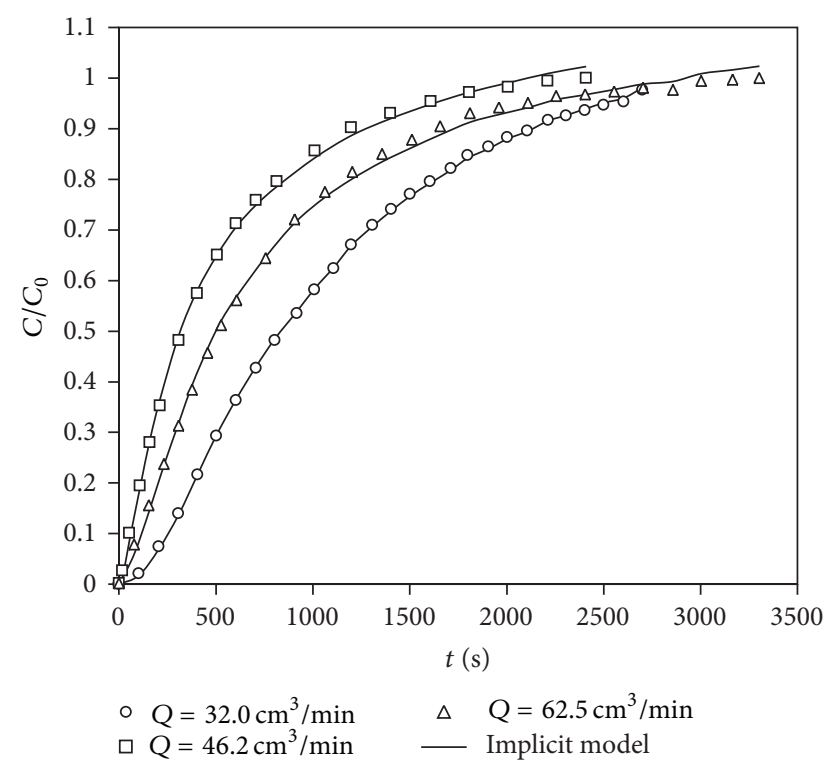

FIGURE 5: Breakthrough curves of propylene adsorption in zeolite $4 \mathrm{~A}$ and different flow rate fitted with (2) [33].

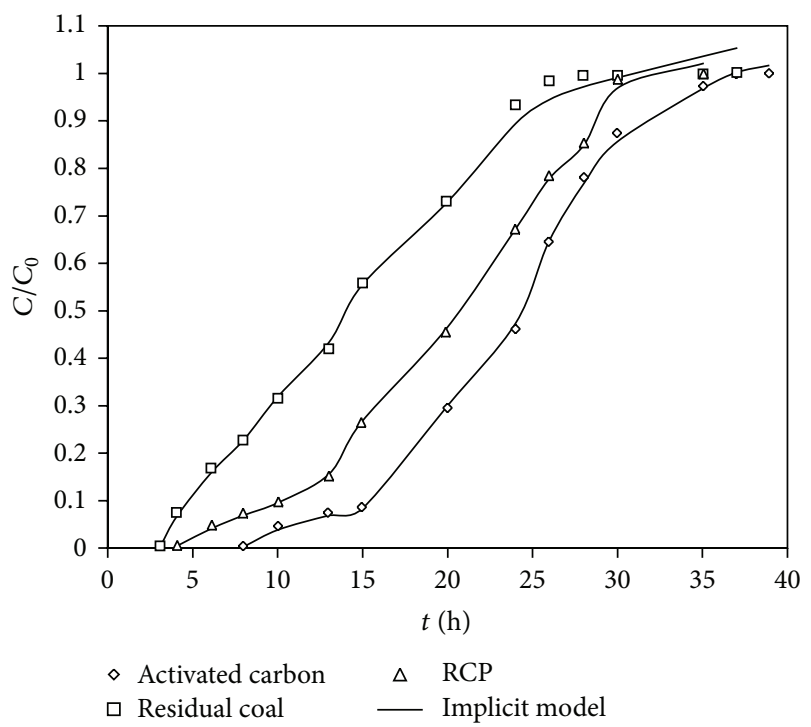

FIGURE 6: Breakthrough curves of phenol adsorption onto different adsorbent fitted with (2) [34].

propriety in equation and consequently logarithmic models give better results which is very obvious. Additionally, the unit of time has no effect on regression quality and just changes the value of constant parameter in models.

To probe the accuracy of the models, our models were compared with other researchers' experimental data. Totally, 18 breakthrough curves have been investigated. The results show that our models can describe breakthrough curves with a wide range of data.

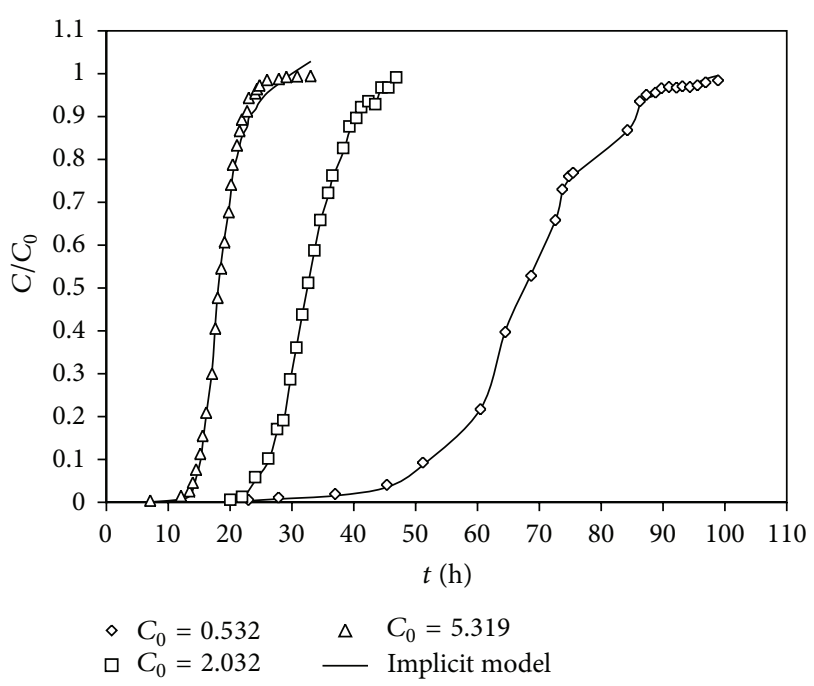

FIGURE 7: Breakthrough curves of phenol adsorption onto resin NDA-100 fitted with (2) [35].

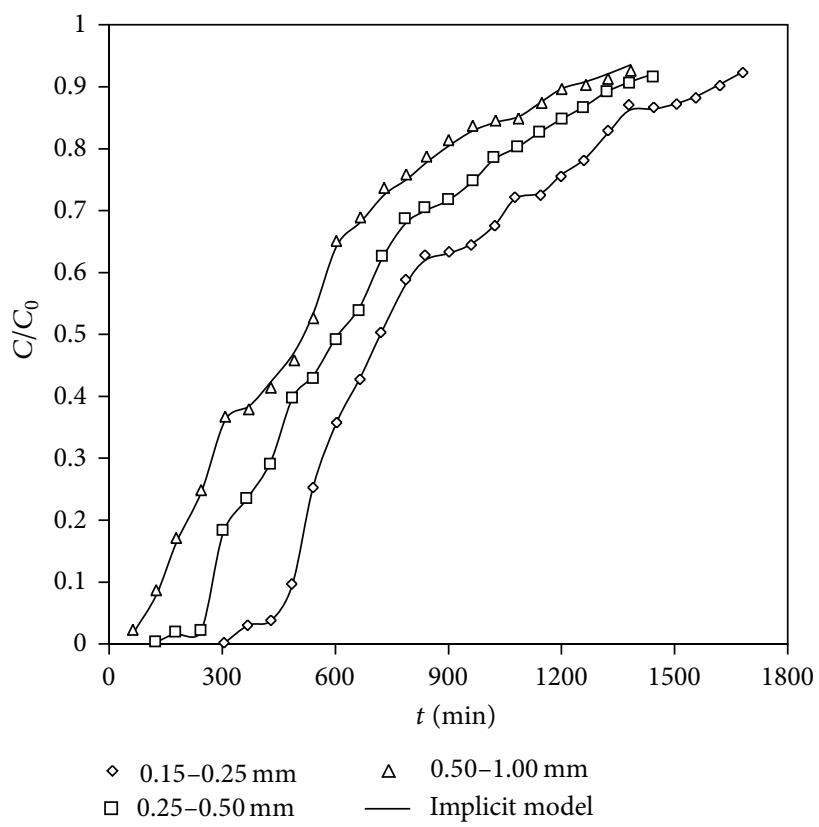

FIGURE 8: Breakthrough curves of $\mathrm{Cr}(\mathrm{VI})$ adsorption onto waste acorn of Quercus ithaburensis fitted with (2) [36].

\section{Nomenclature}

$A-B:$ Equation constant parameters

$C: \quad$ Concentration, $\left(\mathrm{kg} / \mathrm{m}^{3}\right)$

$\mathrm{C} / \mathrm{C}_{0}$ : Relative concentration

$C_{m}$ : Saturation capacity, $\left(\mathrm{kg} / \mathrm{m}^{3}\right)$

$D: \quad$ Equation constant parameter

$D^{\prime}$ : $\quad$ Equation constant parameter

$D_{P}:$ Diffusivity, $\left(\mathrm{m}^{2} / \mathrm{s}\right)$

D.W.: Durbin-Watson statistic

E-J: Equation constant parameters

$E^{\prime}$ : $\quad$ Equation constant parameter 
$K: \quad$ Number of equation parameters

$m-r$ : Equation constant parameters

$m^{\prime}$ : $\quad$ Equation constant parameter

MRPE: Mean absolute percent error

$N$ : Number of data points

$R^{2}$ : Correlation coefficient

$\bar{R}^{2}$ : $\quad$ Adjusted correlation coefficient

SBM: $\quad$ Simulating moving bed

T: $\quad$ Time (s, min or hr)

$t_{F}$ : The time that $C / C_{0}$ reaches to 0.999

$T: \quad$ Temperature, $\left({ }^{\circ} \mathrm{C}\right)$

$\widehat{\varepsilon}$ : $\quad$ Absolute error of regression.

\section{Conflict of Interests}

The authors declare that there is no conflict of interests regarding the publication of this paper.

\section{References}

[1] W. S. Wan Ngah and M. A. K. M. Hanafiah, "Removal of heavy metal ions from wastewater by chemically modified plant wastes as adsorbents: a review," Bioresource Technology, vol. 99, no. 10, pp. 3935-3948, 2008.

[2] A. Radjenovic and J. Malina, "Adsorption of organic acids on blast furnace sludge," Chemical and Biochemical Engineering Quarterly, vol. 23, no. 2, pp. 187-193, 2009.

[3] P. Cambier and G. Sposito, "Adsorption of citric acid by synthetic pseudoboehmite," Clays \& Clay Minerals, vol. 39, no. 4, pp. 369-374, 1991.

[4] P. Cambier, "Interactions of citric acid and synthetic hydroxyaluminum montmorillonite," Clays and Clay Minerals, vol. 39, no. 2, pp. 158-166, 1991.

[5] C. R. Soccol, L. P. S. Vandenberghe, C. Rodrigues, and A. Pandey, "New perspectives for citric acid production and application," Food Technology and Biotechnology, vol. 44, no. 2, pp. 141-149, 2006.

[6] K. Liu, Z. Tong, L. Liu, and X. Feng, "Separation of organic compounds from water by pervaporation in the production of $n$-butyl acetate via esterification by reactive distillation," Journal of Membrane Science, vol. 256, no. 1-2, pp. 193-201, 2005.

[7] Y. Zhang, B. Van der Bruggen, L. Pinoy, and B. Meesschaert, "Separation of nutrient ions and organic compounds from salts in RO concentrates by standard and monovalent selective ion-exchange membranes used in electrodialysis," Journal of Membrane Science, vol. 332, no. 1-2, pp. 104-112, 2009.

[8] F. L. Souza, C. Saéz, M. R. V. Lanza, P. Cañizares, and M. A. Rodrigo, "Is it worth the use of bipolar electrodes in electrolytic wastewater treatment processes?" Chemical Engineering Journal, vol. 264, pp. 310-315, 2015.

[9] Y.-H. Kim, B. Lee, K.-H. Choo, and S.-J. Choi, "Adsorption characteristics of phenolic and amino organic compounds on nano-structured silicas functionalized with phenyl groups," Microporous and Mesoporous Materials, vol. 185, pp. 121-129, 2014.

[10] I. Ali, M. Asim, and T. A. Khan, "Low cost adsorbents for the removal of organic pollutants from wastewater," Journal of Environmental Management, vol. 113, pp. 170-183, 2012.
[11] M. Ahmaruzzaman, "Adsorption of phenolic compounds on low-cost adsorbents: a review," Advances in Colloid and Interface Science, vol. 143, no. 1-2, pp. 48-67, 2008.

[12] N. D. Thanh and H. L. Nhung, "Cellulose modified with citric acid and its absorption of $\mathrm{Pb}^{2+}$ and $\mathrm{Cd}^{2+}$ ions," in Proceeding of 13rd International Electronic Conference on Synthetic Organic Chemistry (ECSOC '13), 2009.

[13] F. Zeinali, A. A. Ghoreyshi, and G. D. Najafpour, "adsorption of dichloromethane from aqueous phase using granular activated carbon: isotherm and break through curve measurements," Middle-East Journal of Scientific Research, vol. 5, no. 4, pp. 191198, 2010.

[14] S. Kulprathipanja, A. Oroskar, and J. Preignitz, Separation of citric acid from fermentation broth with a weakly basic anionic resin absorbent, US patent 4851573, 1989.

[15] X. Cao, H. Yun, and Y. Koo, "Recovery of L-(+)-lactic acid by anion exchange resin Amberlite IRA-400," Biochemical Engineering Journal, vol. 11, no. 2-3, pp. 189-196, 2002.

[16] M. Kitis, T. Karanfil, A. Wigton, and J. E. Kilduff, "Probing reactivity of dissolved organic matter for disinfection by-product formation using XAD-8 resin adsorption and ultrafiltration fractionation," Water Research, vol. 36, no. 15, pp. 3834-3848, 2002.

[17] D. Zhao, L. Zhao, C.-S. Zhu, W.-Q. Huang, and J.-L. Hu, "Waterinsoluble $\beta$-cyclodextrin polymer crosslinked by citric acid: synthesis and adsorption properties toward phenol and methylene blue," Journal of Inclusion Phenomena and Macrocyclic Chemistry, vol. 63, no. 3-4, pp. 195-201, 2009.

[18] E. D. Vega and P. A. Colinas, "Adsorption of fumaric and maleic acids onto hydroxyapatite: a thermodynamic study," Journal of the Argentine Chemical Society, vol. 97, no. 2, pp. 195-206, 2009.

[19] O. Abollino, M. Aceto, M. Malandrino, C. Sarzanini, and E. Mentasti, "Adsorption of heavy metals on Na-montmorillonite. Effect of pH and organic substances," Water Research, vol. 37, no. 7, pp. 1619-1627, 2003.

[20] M. Oh and M. A. Tshabalala, "Pelletized ponderosa pine bark for adsorption of toxic heavy metals from water," BioResources, vol. 2, no. 1, pp. 66-81, 2007.

[21] S. A. Ghorbanian, M. Davoudinejad, S. R. Radpour, and A. Khapay, "Investigation of breakthrough curves of citric acid adsorption," Chemical and Biochemical Engineering Quarterly, vol. 28, no. 3, pp. 329-336, 2014.

[22] W. Takatsuji and H. Yoshida, "Removal of organic acids from wine by adsorption on weakly basic ion exchangers. Equilibria for single and binary systems," Separation Science and Technology, vol. 29, no. 11, pp. 1473-1490, 1994.

[23] P. Gluszcz, T. Jamroz, B. Sencio, and S. Ledakowicz, "Equilibrium and dynamic investigations of organic acids adsorption onto ion-exchange resins," Bioprocess and Biosystems Engineering, vol. 26, no. 3, pp. 185-190, 2004.

[24] A. Mokrini, D. Ousse, and S. Esplugas, "Oxidation of aromatic compounds with UV radiation/ozone/hydrogen peroxide," Water Science and Technology, vol. 35, no. 4, pp. 95-102, 1997.

[25] N. Z. Misak, "Some aspects of the application of adsorption isotherms to ion exchange reactions," Reactive and Functional Polymers, vol. 43, no. 1, pp. 153-164, 2000.

[26] A. Kodama, "Cross-contamination test of an enthalpy wheel loading a strong acidic cation ion-exchange resin or $3 \mathrm{~A}$ zeolite as a desiccant material," Journal of Chemical Engineering of Japan, vol. 43, no. 10, pp. 901-905, 2010. 
[27] M. D. LeVan, G. Carta, and C. M. Yon, "Adsorption and ion exchange," in Perry's Chemical Engineers Handbook, McGraw Hill, New York, NY, USA, 6th edition, 1997.

[28] G. Wood, "Organic vapor respirator cartridge breakthrough curve analysis," Journal of International Society for Respiratory Protection, vol. 10, no. 4, pp. 5-12, 1993.

[29] C. C. Rodrigues, D. de Moraes Jr., S. W. da Nóbrega, and M. G. Barboza, "Ammonia adsorption in a fixed bed of activated carbon," Bioresource Technology, vol. 98, no. 4, pp. 886-891, 2007.

[30] Quantitative Micro Software LLC, EViews 4 User's Guide, Quantitative Micro Software LLC, 2002.

[31] L. Lv, Y. Zhang, K. Wang, A. K. Ray, and X. S. Zhao, "Modeling of the adsorption breakthrough behaviors of $\mathrm{Pb}^{2+}$ in a fixed bed of ETS-10 adsorbent," Journal of Colloid and Interface Science, vol. 325, no. 1, pp. 57-63, 2008.

[32] J. Romero-González, J. C. Walton, J. R. Peralta-Videa, E. Rodríguez, J. Romero, and J. L. Gardea-Torresdey, "Modeling the adsorption of $\mathrm{Cr}$ (III) from aqueous solution onto Agave lechuguilla biomass: study of the advective and dispersive transport," Journal of Hazardous Materials, vol. 161, no. 1, pp. 360-365, 2009.

[33] C. A. Grande and A. E. Rodrigues, "Adsorption kinetics of propane and propylene in zeolite 4A," Chemical Engineering Research and Design, vol. 82, no. 12, pp. 1604-1612, 2004.

[34] M. Ahmaruzzaman and D. K. Sharma, "Adsorption of phenols from wastewater," Journal of Colloid and Interface Science, vol. 287, no. 1, pp. 14-24, 2005.

[35] B. C. Pan, F. W. Meng, X. Q. Chen et al., "Application of an effective method in predicting breakthrough curves of fixedbed adsorption onto resin adsorbent," Journal of Hazardous Materials, vol. 124, no. 1-3, pp. 74-80, 2005.

[36] E. Malkoc, Y. Nuhoglu, and Y. Abali, "Cr(VI) adsorption by waste acorn of Quercus ithaburensis in fixed beds: prediction of breakthrough curves," Chemical Engineering Journal, vol. 119, no. 1, pp. 61-68, 2006. 

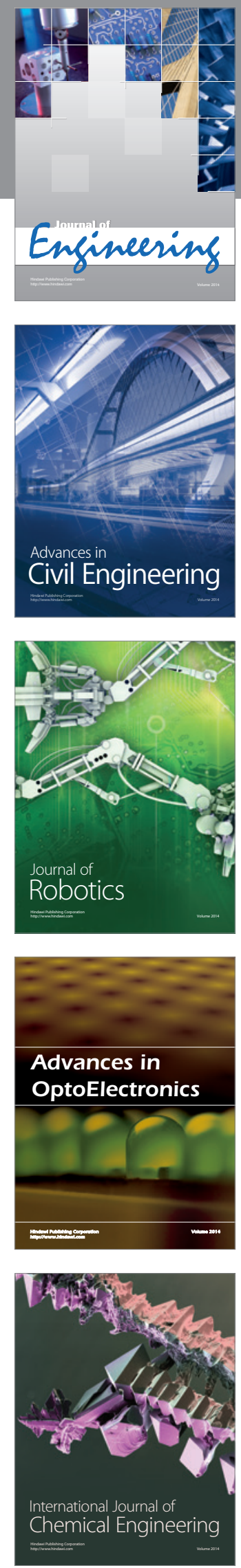

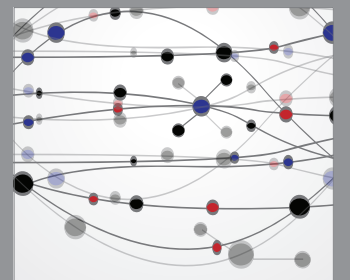

The Scientific World Journal
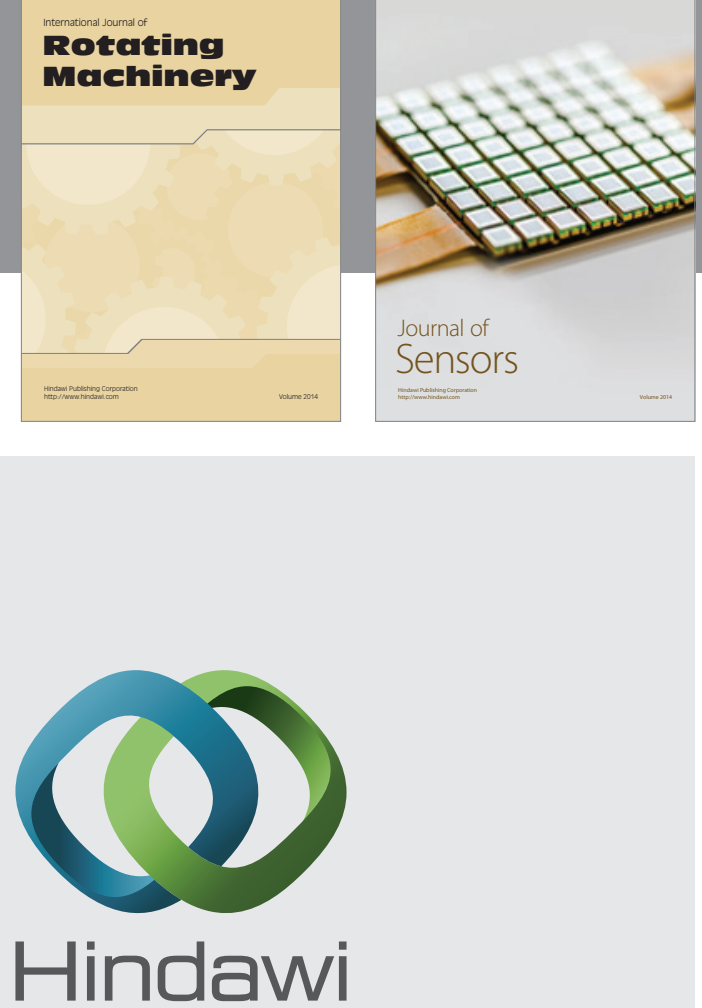

Submit your manuscripts at http://www.hindawi.com
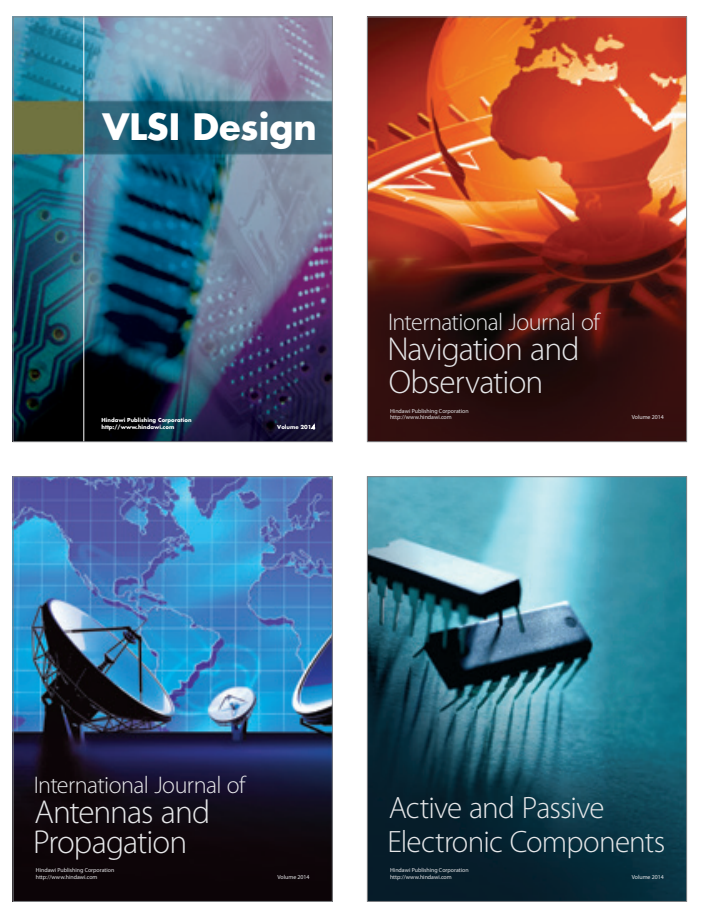
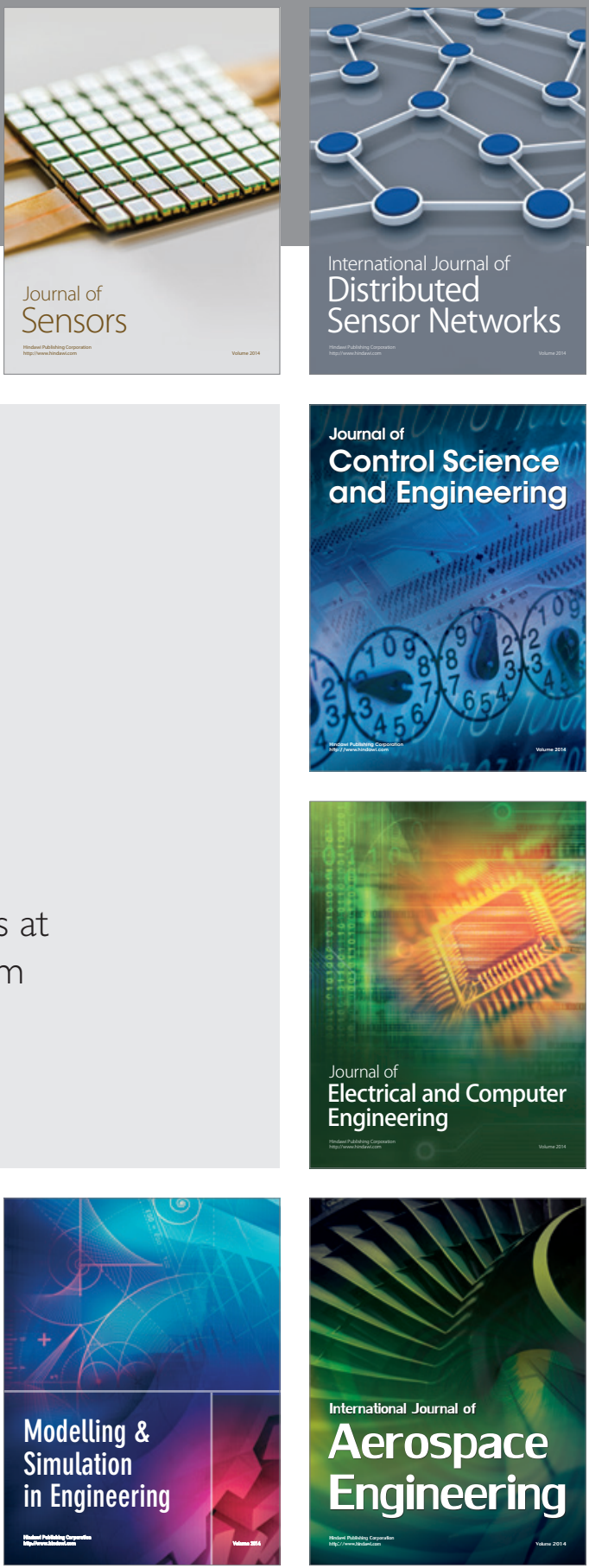

Journal of

Control Science

and Engineering
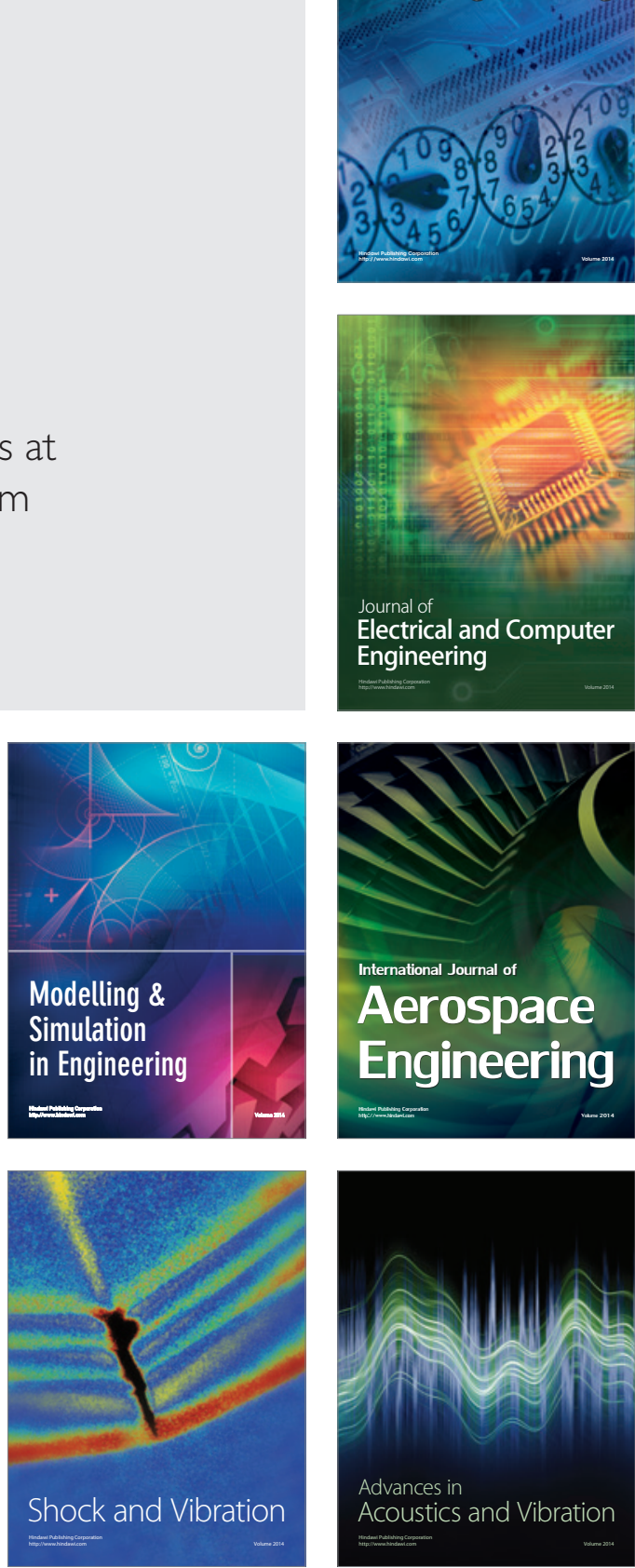